\title{
Effect of Impeller Agitation on Preparation of Tetra-n-Butyl Ammonium Bromide Semiclathrate Hydrate Slurries
}

\author{
Shunsuke Hashimoto, Hiroyuki Ito, Kazunari Ohgaki, and Yoshiro Inoue \\ Division of Chemical Engineering, Graduate School of Engineering Science, Osaka University, 1-3 Machikaneyama, Toyonaka, \\ Osaka 560-8531, Japan \\ Correspondence should be addressed to Shunsuke Hashimoto, shunsuke@cheng.es.osaka-u.ac.jp
}

Received 18 October 2011; Revised 28 December 2011; Accepted 15 January 2012

Academic Editor: Naoto Ohmura

Copyright (๑) 2012 Shunsuke Hashimoto et al. This is an open access article distributed under the Creative Commons Attribution License, which permits unrestricted use, distribution, and reproduction in any medium, provided the original work is properly cited.

\begin{abstract}
The slurries-containing tetra- $n$-butyl ammonium bromide (TBAB) solution and its semiclathrate hydrate have attracted a lot of interest as latent heat transport media. These hydrate slurries contain some microparticles of crystal, and the size and shape of these hydrate particles could affect the mobility of slurries. Hence, it is essential to investigate the efficient hydrate-slurry preparation methods and the effect of hydrate particles on the fluid property of slurries for the application to latent heat transport media. In the present study, the effect of agitation on particle size distribution and aggregation of particles was studied to prepare easily flowing TBAB hydrate slurries that were suitable for fluid transport. First of all, the effects of impeller rotational speed and impeller type on the particle size and frequency of aggregation were investigated. The results suggested that the particle size distribution and the frequency of particle aggregation are strongly affected by the intensity of shear rate and its uniformity, which was controllable with impeller type and its rotation speed.
\end{abstract}

\section{Introduction}

Recently, a large-scale district (regional) cooling system has attracted attention of many researchers because it works on saving energy and global sustainability due to its high performance of utilization of exhausted heat from large plants or factories [1]. In such system, the pumping energy loss due to the transportation of heat media is not small. To solve this problem, a high-density heat transportation system involving slurries with phase change materials (hereafter, PCM) having latent heat has been developed, for example, ice/water slurries [2]. The utilization of such PCM slurries can reduce flow rate of heat media, since latent heat of some materials is much larger than sensible heat. Fukushima et al. [3] reported the ability of slurries-containing tetra- $n$ butyl ammonium bromide (hereafter, TBAB) semiclathrate hydrate and its solution as latent-heat transport media, which was more favorable than ice/water system because they can be operated at relatively high temperature (ca. $285 \mathrm{~K}$ ) and atmospheric pressure. Unlike ordinary gas hydrates, in these semiclathrate hydrates, the quaternary ammonium cation and anion are incorporated with the hydrogen bonds of water molecules to construct the hydrate cage [4]. In addition, four butyl groups are one-by-one encaged with a large cage separately in this semiclathrate system. There are various reports about the crystal structure and the role of bromine for the TBAB hydrates $[4,5]$. The hydration numbers of these structures are 26 and 38, which are described as Type A (tetragonal) and Type B (orthorhombic), respectively $[5,6]$. The concentration of aqueous TBAB solutions results in differences of the crystal structure and thermodynamic stability of TBAB hydrate. TBAB semiclathrate hydrates have become the subject of much attention as an attractive medium for not only refrigerant but also $\mathrm{H}_{2}$ storage [7-9].

There are a few reports about thermodynamic properties such as phase equilibria and dissociation enthalpy of TBAB hydrate [10] and about rheological property of these hydrate slurries [11] for the application to latent heat transport media. These hydrate slurries contain some microparticles of crystal, and the size and shape of these hydrate particles may affect the mobility of slurries. In addition, with the view of heat conductivity, it is necessary to make hydrate particles smaller and subglobular and to control their agglomerating property so that hydrate particles dissociate rapidly 
and uniformly. Therefore, it is essential to investigate the efficient preparation method of hydrate slurries and the effect of hydrate particles on the fluid property of slurries for the application to latent heat transport media. There are some reference papers that investigate the effect of impeller agitation and bottom shape of stirred tank on the particle-size distribution and/or dispersion efficiency in the suspension systems containing polymer particles [1214]. There, the dispersion efficiency such as the agitating speed for complete floating of solid particles was mainly investigated. In addition, some unique and complicated techniques such as multistage impeller system and unsteady agitation were usually utilized for the dispersion of solid particles. However, there are few findings that discuss the basic relation between the particle size and/or shape and the intensity and configuration of shear field. Furthermore, there is no report about the control of particle property for clathrate hydrates by means of impeller agitation.

Generally, impeller agitation has been adopted as the method for efficient crystallization of hydrate particles. However, there are few reports about the control of particle property for clathrate hydrates by means of impeller agitation. In the present study, we aim at searching for the favorable condition of agitation that minimizes the total power needed for both agitation and pumping of the prepared hydrate slurries and the effect of agitation on particle-size distribution and aggregation of particles to prepare $\mathrm{TBAB}$ hydrate slurries that easily flow and are suitable for fluid transport. In this paper, the effects of impeller rotational speed and impeller type on the particle size and frequency of aggregation are investigated. In addition, the key factor to control particle characteristics in $\mathrm{TBAB}$ hydrate slurries is briefly discussed.

\section{Experimental Section}

2.1. Materials. Research grade TBAB (mole fraction purity 0.980) was obtained from Wako Pure Chemical Industries, Ltd. TBAB was used without further purifications. In addition, deionized water was produced using water-manufacturing equipment made by Nihon Millipore K. K.

2.2. Apparatus and Procedures. The experimental apparatus in the present study consisted of the following parts: acrylic cylindrical vessel (diameter, $D: 120 \mathrm{~mm}$, height, $H: 200 \mathrm{~mm}$, handcrafted), three types of agitating impellers (handcrafted), agitating motors (HEIDON, BLh-300), torque meter (type: YT, Shintou Kagaku, Co., Ltd.), temperature controller (TAITEC, CL-80R), and CCD camera (KEYENCE, VH5910). Figure 1 shows the details of three types of agitating impellers used in the present study: two-bladed paddle (2-BP), Maxblend (Sumitomo Heavy Industries, Ltd., MB), and rotational cylinder (RC). The 2-BP impeller was located at a height of $60 \mathrm{~mm}$. The diameter of shaft was $8 \mathrm{~mm}$. Four baffles (width: $12 \mathrm{~mm}$ ) were attached in the vessel with 2$\mathrm{BP}$ and $\mathrm{MB}$, while no baffle was attached in the case of $\mathrm{RC}$ because uniform flow field was created. In addition, the characteristics of three impellers are summarized in Table 1
TABLE 1: The characteristics of three impellers used in the present study.

\begin{tabular}{lcccc}
\hline & $n_{r}(\mathrm{rpm})$ & $2-\mathrm{BP}$ & $\mathrm{MB}$ & $\mathrm{RC}$ \\
\hline$K$ & - & 10 & 20 & - \\
\hline \multirow{3}{*}{$\gamma_{\mathrm{av}}\left(\mathrm{s}^{-1}\right)$} & 100 & 17 & 33 & 10.5 \\
& 200 & - & - & 21.0 \\
\hline $\begin{array}{l}\text { Uniformity of } \\
\text { shear rate }\end{array}$ & 300 & 50 & 100 & 31.5 \\
\hline
\end{tabular}
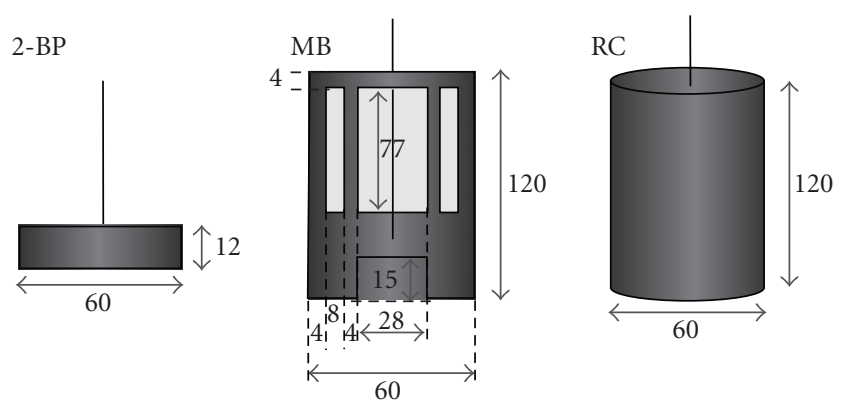

FIGURE 1: The schematic illustration of three types of impellers used in the present study (the unit of length is $\mathrm{mm}$ ).

(details for the velocity field of three types of impeller are shown in the former part of Section 3). The average shear rate, $\gamma_{\mathrm{av}}$ can be calculated by use of Metzner and Otto's equation [15] as follows:

$$
\gamma_{\mathrm{av}}=K \cdot n_{r}
$$

where $K$ (depending on the type of impeller) and $n_{r}$ stand for Metzner and Otto's constant and the rotation speed of impeller, respectively. In this case, $K$ was equivalent to 10 for 2-BP and 20 for MB, respectively, which was estimated and correlated systematically by Kamei et al. [16]. In the case of RC (simple shear field), $\gamma_{\mathrm{av}}$ can be generally estimated by the following equation:

$$
\gamma_{\mathrm{av}}=\frac{\left(2 \pi n_{r} y\right)}{(1-y)},
$$

where $y$ stands for the diameter ratio of cylinder and vessel (in the present study, $y=0.5$ ). The $\gamma_{\mathrm{av}}$ values are also listed in Table 1 with $K$ value.

Figure 2 shows the thermodynamic stability of TBAB hydrate (temperature, $T$-concentration, $C$ diagram) at atmospheric pressure. The TBAB hydrate is stable at the temperatures below the line that is equivalent to the stability boundary of TBAB hydrate. As shown in Figure 2, the stoichiometric concentration of Type A TBAB hydrate is $40.5 \mathrm{wt} \%$ where the TBAB hydrate can exist stably at $c a$. $285 \mathrm{~K}$. In the present study, the hydrate fraction in slurries, and $H_{f}$ was determined by the following equation:

$$
H_{f}=\frac{\left(C_{i}-C_{\mathrm{eq}}\right)}{\left(C_{s}-C_{\mathrm{eq}}\right)},
$$




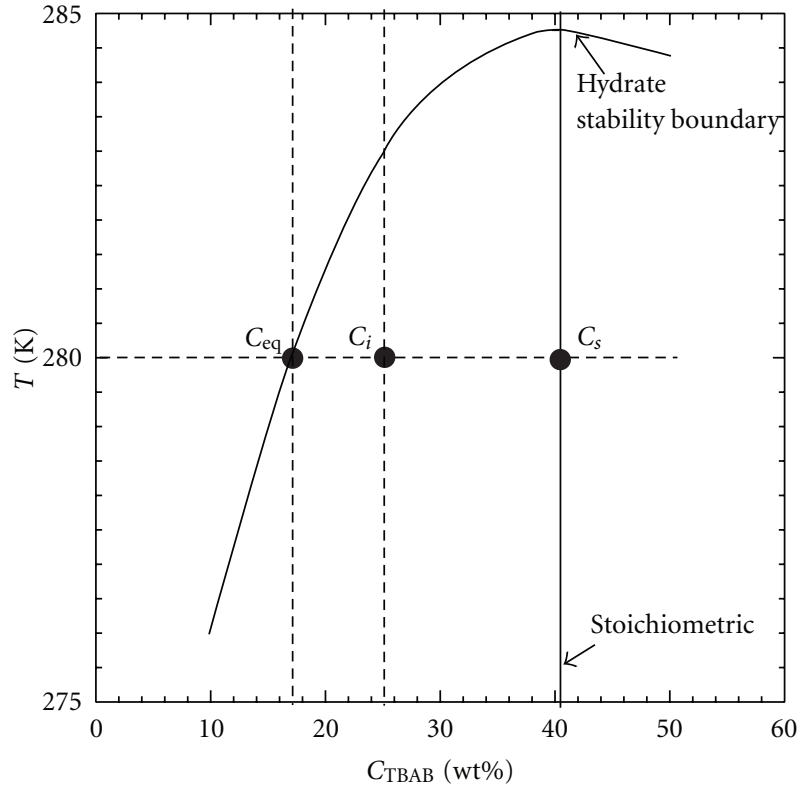

FIgURE 2: Temperature composition diagram for the TBAB + water mixed system containing stability boundary of Type A (tetragonal) hydrate $[3,10]$.

where $C_{i}, C_{\mathrm{eq}}$, and $C_{s}$ stand for the initial concentration of $\mathrm{TBAB}$ in aqueous solution, steady concentration of TBAB in the liquid phase of slurries, and stoichiometric concentration of Type A TBAB hydrate, respectively. In general, $H_{f}$ decreases monotonically as temperature rises. In the present study, $20 \mathrm{wt} \%$ of TBAB in aqueous solution was adopted as a working fluid.

Firstly, the working fluid (20 wt $\%$ solution of TBAB) was poured into the vessel up to $120 \mathrm{~mm}$ (liquid height, $h=D)$. Then, the fluid was cooled down up to $280.6 \mathrm{~K}$ (subcooling degree is $c a .0 .7 \mathrm{~K}$ and then $H_{f}=c a .0 .1$ ) and the rotation of impeller was started. After the system reached the cyclostationary state, some seed crystals of Type A TBAB hydrate, which were prepared in advance and annealed at $280.6 \mathrm{~K}$, were injected into the vessel, and then crystallization occurred. Raman spectroscopy preliminarily revealed that only Type A TBAB hydrate formed under the present experimental conditions [8]. In this case, it was confirmed that the particles of TBAB hydrate reached the steady state after an hour. Hence, appropriate amount of hydrate particles was removed up from the mother fluid and observed by use of CCD camera on the petri dish that was chilled with Peltier device. Typical picture of hydrate particles was shown in Figure 3. In the present study, 500 particles in total were used for particle size analyses of each experimental run. The particle diameter was defined as the major axis of rod-like hydrate particle. In addition, the aggregation particle was defined as the particle that consisted of more than two particles. The density of Type A TBAB hydrate particle was measured by means of falling ball method. The density of hydrate particle was comparable with the theoretical value, which could be calculated from the lattice constant of unit cell for tetragonal Type A TBAB hydrate. Additionally, it was slightly larger than that of aqueous
TABLE 2: The summary of experimental results. The average diameter means the overall average value of all TBAB hydrate particles observed in each experimental run.

\begin{tabular}{lcccc}
\hline Impeller & $n_{r}(\mathrm{rpm})$ & $\begin{array}{c}\text { Average } \\
\text { diameter }(\mathrm{mm})\end{array}$ & $\begin{array}{c}\text { Aggregation } \\
\text { frequency }(\%)\end{array}$ & $P(\mathrm{~W})$ \\
\hline \multirow{2}{*}{ - $\mathrm{BP}$} & 100 & 1.32 & 14.1 & 0.02 \\
& 300 & 1.16 & 1.5 & 0.21 \\
\hline \multirow{2}{*}{$\mathrm{MB}$} & 100 & 1.13 & 6.3 & 0.04 \\
& 300 & 0.77 & 0.4 & 1.08 \\
\hline \multirow{2}{*}{$\mathrm{RC}$} & 100 & 0.75 & 20.1 & 0.01 \\
& 200 & 0.75 & 16.6 & 0.03 \\
& 300 & 0.76 & 16.2 & 0.09 \\
\hline
\end{tabular}

solution. In this case, upward flows above a certain level by external force such as impeller rotation are required to float solid particles completely, which is well known as a criterion of impeller rotational speed for the complete floating of solid particles [17]. In the present study, impeller rotational speed in all experiments was more than this threshold value. Hence, it is reasonable to decide that the hydrate particles float completely and well dispersed in the vessel.

The required power for mixing, $P$, was obtained from rotational torque, $T_{r}$, of impeller shaft by the following equation:

$$
P=2 \pi n_{r} T_{r} .
$$

\section{Results and Discussion}

Prior to experiments, the flow velocity vector patterns of three types of impeller were obtained from the numerical simulation by the use of commercial CFD software, Rflow (RFLOW, Co., Ltd.). Figure 4 shows the flow velocity vector patterns of (a) 2-BP (with 4 baffles), (b) MB (with 4 baffles), and (c) RC (without baffles). The density and viscosity of fluid were set equal to those of TBAB aqueous solution $\left(1080 \mathrm{~kg} / \mathrm{m}^{3}\right.$ and $0.003 \mathrm{~Pa} \cdot \mathrm{s}$, resp.), and general $k-\varepsilon$ model was adopted as a turbulent flow model. In calculations, the $n_{r}$ was set at $100 \mathrm{rpm}$. As it can be seen in Figure 4, 2BP generates nonuniform velocity field in both vertical and horizontal directions, where flow velocity is locally high near the impeller and low near the wall. On the other hand, in the case of RC, uniform circulating flow (a large vortex) is vertically generated, and, in particular, uniform rotational flow is circumferentially created. In the case of MB, although there are locally high and/or low flow regions, overall relatively uniform circulating flow is vertically generated. At $n_{r}=300 \mathrm{rpm}$, the flow is somewhat intensified, while the flow pattern remains the same in all impellers.

The Experimental Data. Particle size and distribution, aggregation frequency of particles, and required power for the agitation of slurries obtained in the present study are summarized in Table 2. Hereafter, the detailed discussion about the difference in results for the three impellers is given in each section. 


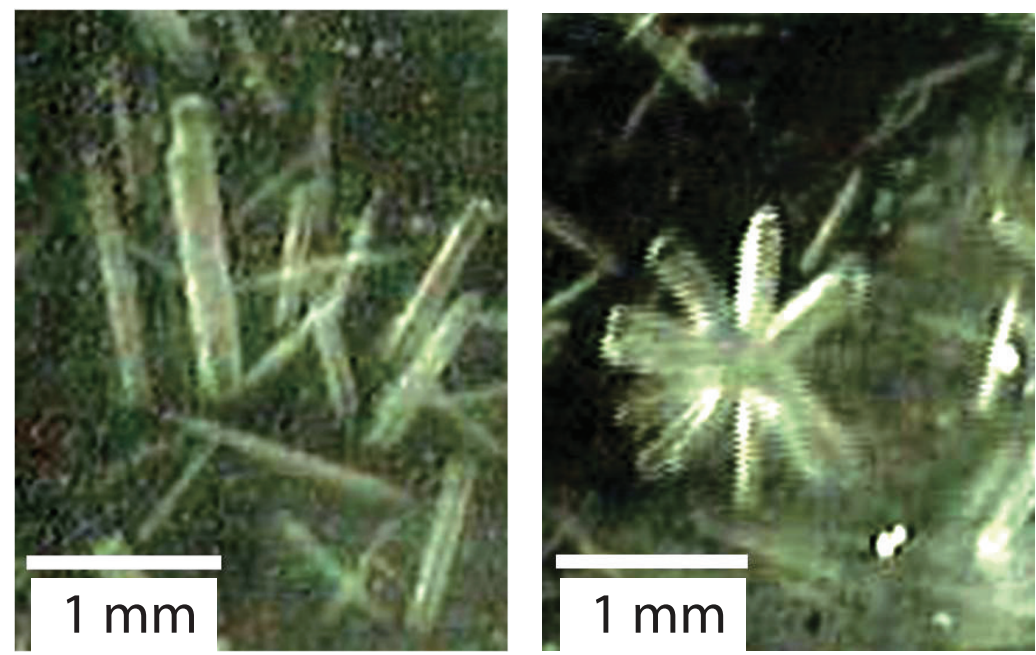

Figure 3: The photos of TBAB hydrate; (a) typical rod-like particles, (b) typical aggregation particles.

3.1. Particle Size and Its Distribution. Figure 5 shows the particle diameter of TBAB hydrates and its distribution for three types of impeller. In the case with 2-BP and RC, the particle diameter and its distribution do not change with the increase in shear rate. On the other hand, they change drastically as shear rate increases in the case with $\mathrm{MB}$. This indicates that the growth of hydrate particle is suppressed considerably under the shear conditions above a certain level. In addition, even though the average shear rate of $\mathrm{RC}$ is lowest among three impellers at the equal speed of impeller rotation, the particle diameter and its distribution are relatively small in RC. Hence, the uniformity of shear rate is one of dominant factors for the control of particle diameter and its distribution. In fact, the 2-BP that generates nonuniform flow field exhibits broad size distribution characteristics of hydrate particles. Although the shear rate of $\mathrm{MB}$ is inhomogeneous compared with that of $\mathrm{RC}$, the average shear rate of $\mathrm{MB}$ at $n_{r}=300 \mathrm{rpm}$ is relatively very high (Table 1). Consequently, it is suggested that the local region of low shear rate can be kept away in the MB due to its large area of blade and particle diameter would become small.

3.2. Aggregation Frequency of Hydrate Particle. The open symbols in Figure 6 stand for the aggregation frequency of hydrate particles. The aggregation frequency becomes smaller in the order of RC, 2-BP, and MB. In addition, it becomes small as the shear rate increases. This indicates that the aggregation of hydrate particles is suppressed by the collision between hydrate particles and impeller blades and/or baffles, and the presence of field of locally high shear rate.

3.3. Required Power for the Agitation of Hydrate Slurries. The closed symbols in Figure 6 represent the required power to agitate hydrate slurries. As mentioned previously, MB can create the flow field that has a distinct advantage for the control of hydrate particles and limit their aggregation. As expected, however, the required power for agitation in $\mathrm{MB}$ is extremely large compared to the other impellers, which is due to the relatively large area of its impeller blade. Incidentally, it is experimentally confirmed that the required power for the agitation of hydrate slurries is almost same as (slightly larger than) that of aqueous solution under the present conditions of hydrate fraction, where the difference between them is at most ca. 0.002 W.

3.4. Conceptual Impeller for Efficient Agitation of TBAB Hydrate Slurries. Based on the present experimental results, to prepare the hydrate particles that have small diameter and sharp distribution of diameter, three factors are essential. They are (1) uniformity of shear rate, (2) absence of the local region of low shear rate, and (3) presence of field that has locally high shear rate (or the collision between hydrate particles and impeller blade). Herein, a conceptual impeller that can satisfy above key factors was developed. Figure 7 shows the schematic illustration of this conceptual impeller, velocity vector of its pattern of flow, and its characteristics of generated hydrate particle. As shown in Figure 7(a), this conceptual impeller consists of 2-bladed paddle blade (bottom) and cylinder (top). Figure 7(b) indicates that this conceptual impeller can generate both the region of locally high shear rate (bottom side) and that of uniform shear rate (top side) at the same time. As a result, the uniform and nearly steady circulating flow can be generated. Needless to say, this impeller can prevent the region of low shear rate. In addition, it is expected that the part of impeller blade can prevent the aggregation of hydrate particles. In fact, as shown in Figure 7(c), this conceptual impeller can prepare TBAB hydrate particles that have uniform diameter, and their average diameter is relatively small $(0.804 \mathrm{~mm})$. Additionally, the aggregation frequency of TBAB hydrate for this impeller is relatively low (5.6\%) and the required power is also low $(0.180 \mathrm{~W})$. After all, this conceptual impeller manufactured based on some experimentally obtained dominant factors has good performance for the preparation of TBAB hydrate particles. The findings obtained in the present study are useful for the development of new impeller, which is suitable 


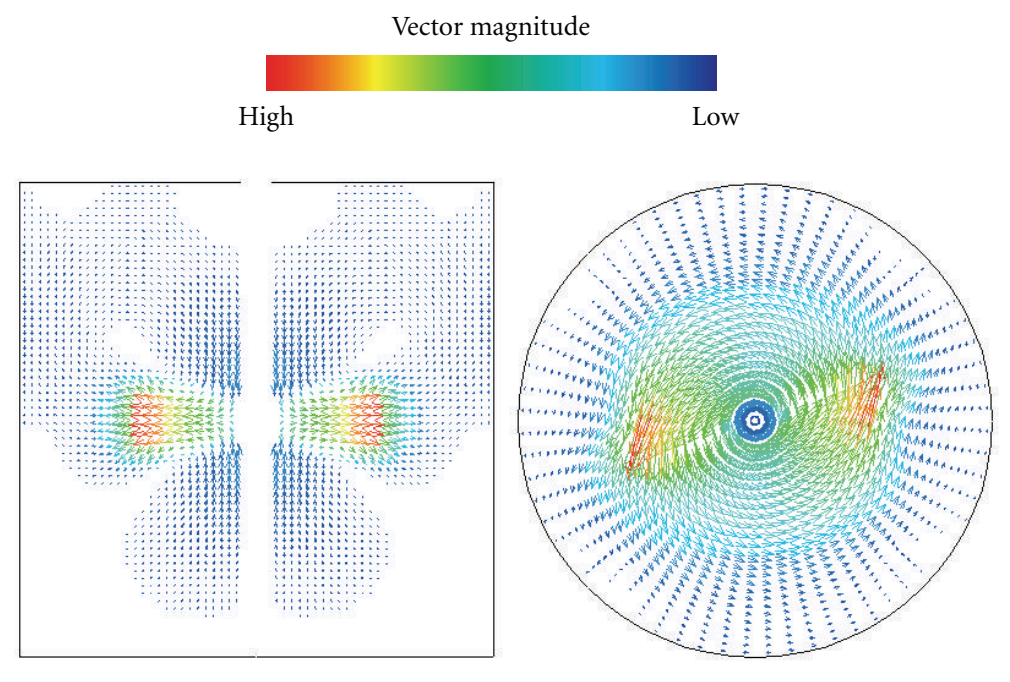

(a)
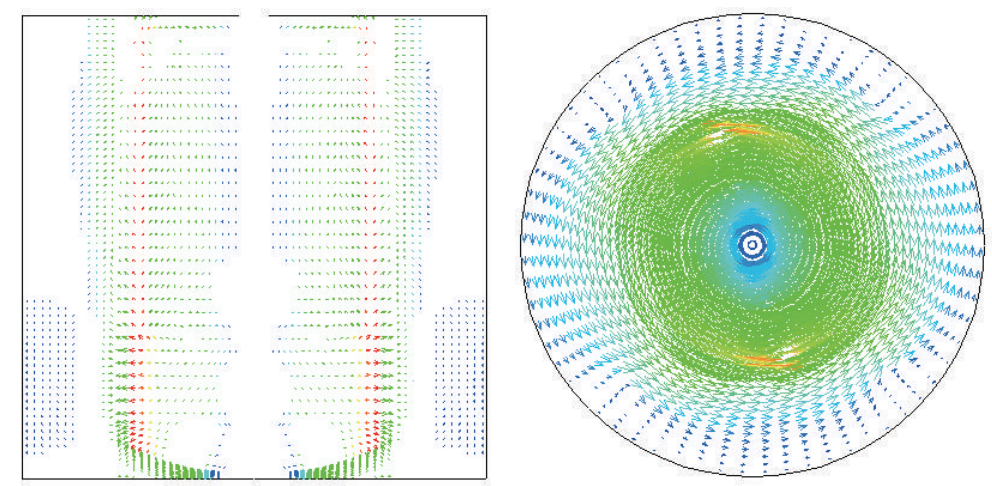

(b)
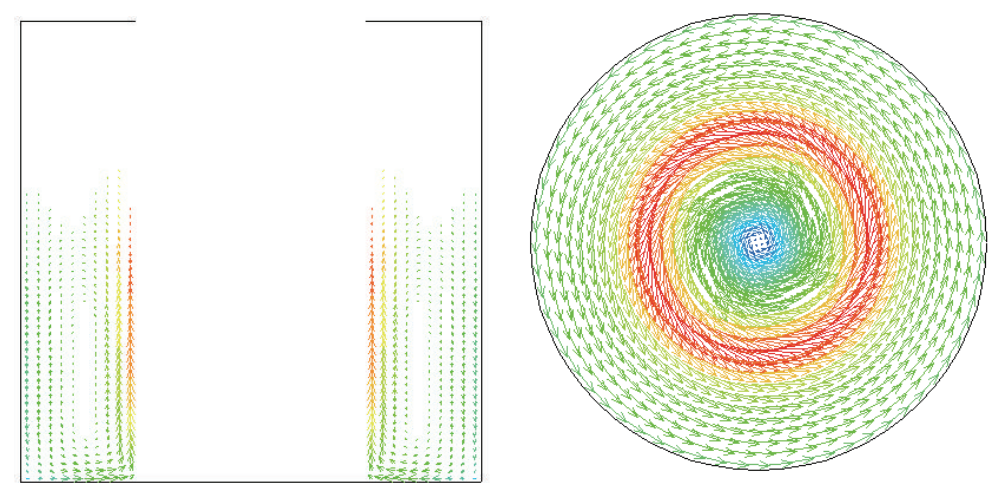

(c)

FIGURE 4: The flow velocity-vector patterns of three types of impellers in the vertical and horizontal directions (cross-section containing impeller blade and shaft) ( $n_{r}=100 \mathrm{rpm}$ ); (a) 2-BP (with 4 baffles), (b) MB (with 4 baffles), (c) RC (without baffles).

for the preparation of TBAB hydrate slurries that easily flow and are suitable for fluid transport.

\section{Conclusion}

To prepare TBAB hydrate slurries that easily flow and are suitable for fluid transport, the effects of impeller rotational speed and impeller type on the particle size and frequency of aggregation have been investigated. The experimental findings are simply summarized in Table 3. For the preparation of hydrate particles that have small diameter and sharp distribution of diameter, three factors and their balances are essential as follows: (1) uniformity of shear rate, (2) absence of the region of low shear rate, and (3) presence of field that has locally high shear rate. Based on these factors, a new conceptual impeller has been proposed, which consists of 2-bladed paddle blade (bottom) and cylinder (top). This conceptual impeller has succeeded in the preparation of smaller and uniform TBAB hydrate particles with relatively low agitation power. 


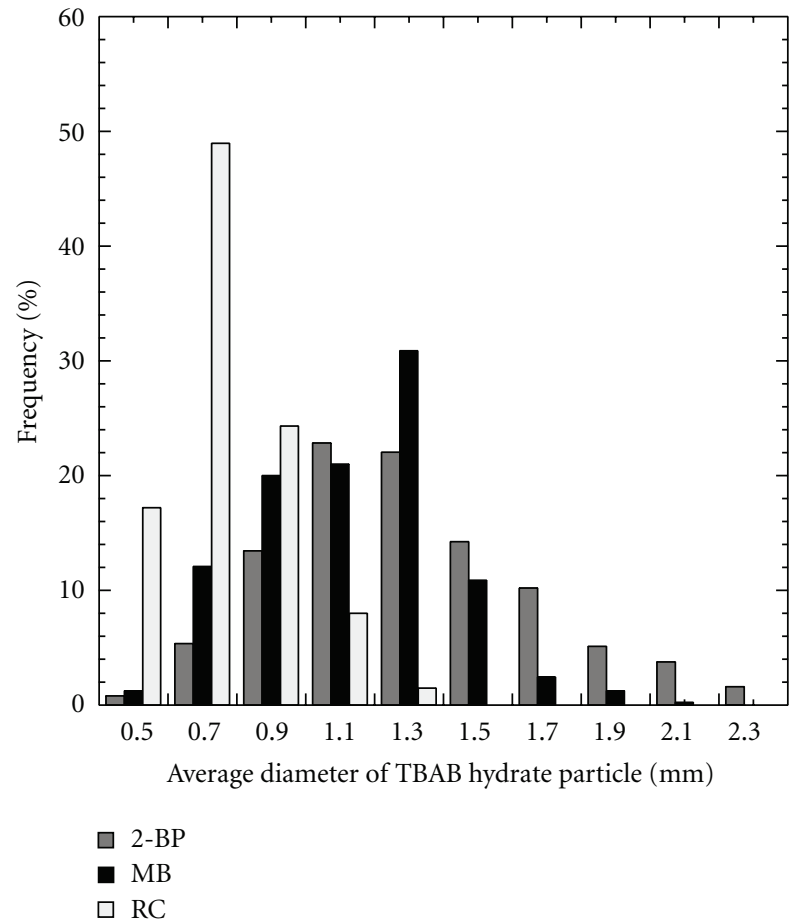

(a)

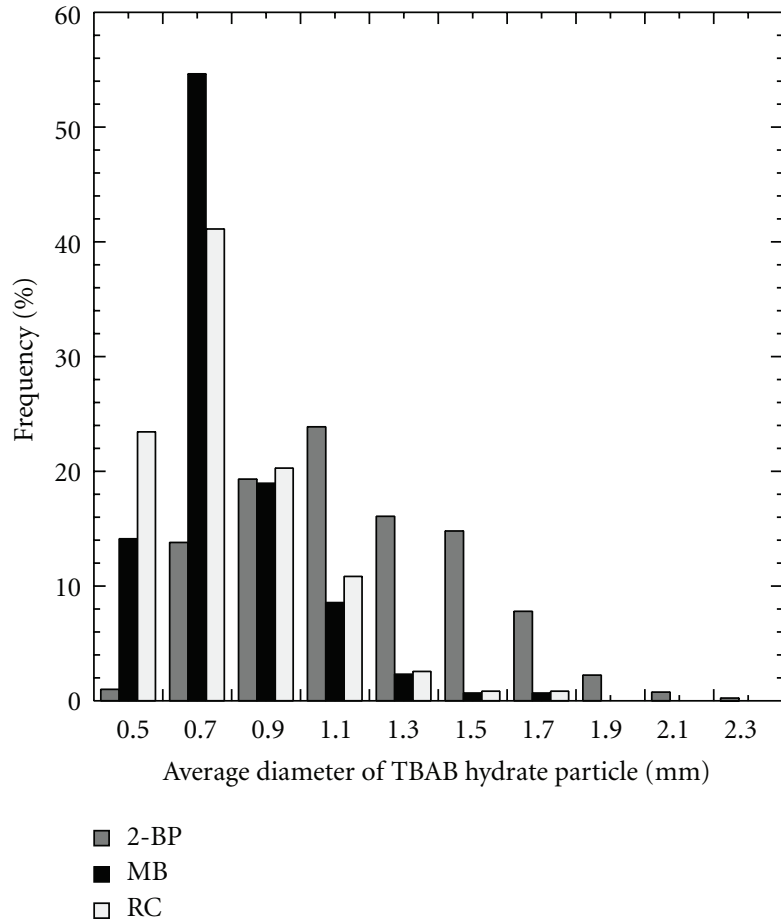

(b)

Figure 5: The particle diameter of TBAB hydrate and its distribution for three types of impeller; (a) $n_{r}=100 \mathrm{rpm}$, (b) $n_{r}=300 \mathrm{rpm}$.

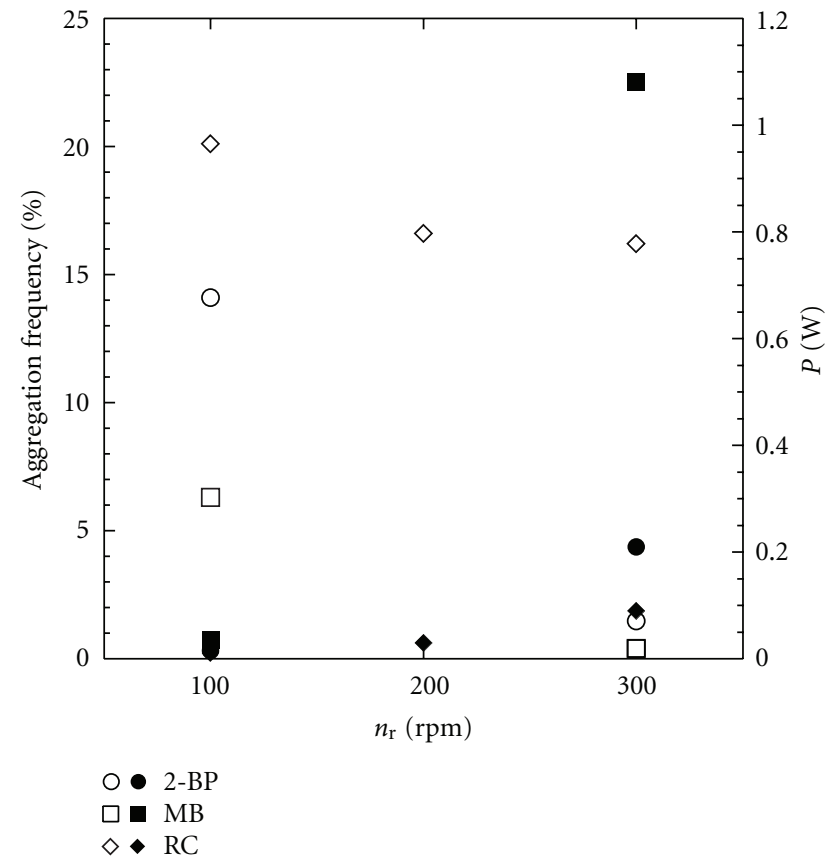

FIGURE 6: The aggregation frequency of hydrate particles (open symbols, left axis) and required power to agitate hydrate slurries (closed symbols, right axis) for three types of impeller.

\section{Notations}

$C$ : Concentration, wt $\%$

$D$ : Diameter of vessel, $\mathrm{m}$

$H$ : Height of vessel, $\mathrm{m}$
TABLE 3: The relative results of important factors for the preparation of TBAB hydrate slurries in various impellers. Herein, the boundary between "small" and "large" is defined at the value of $1.0 \mathrm{~mm}$ (particle diameter) and $1.0 \mathrm{~W}$ (required power). The indexes of "low" and "high" mean the value of $<5 \%$ and $>10 \%$, respectively, and "middle" does the value between them.

\begin{tabular}{lcccc}
\hline Impeller & $n_{r}(\mathrm{rpm})$ & $\begin{array}{c}\text { Particle } \\
\text { diameter }\end{array}$ & $\begin{array}{c}\text { Aggregation } \\
\text { frequency }\end{array}$ & $\begin{array}{c}\text { Required } \\
\text { power }\end{array}$ \\
\hline \multirow{2}{*}{ 2-BP } & 100 & Large & High & Small \\
& 300 & Large & Low & Small \\
\hline \multirow{2}{*}{ MB } & 100 & Large & Middle & Small \\
& 300 & Small & Low & Large \\
\multirow{2}{*}{ RC } & 100 & Small & High & Small \\
& 300 & Small & High & Small \\
\hline Conceptual & 300 & Small & Low & Small \\
\hline
\end{tabular}

$h$ : Height of working fluid, $\mathrm{m}$

$H_{f}:$ Hydrate fraction in slurries

$n_{r}$ : Rotation speed of impeller, rpm

$P: \quad$ Required power for agitation, $\mathrm{W}$

T: Temperature, $\mathrm{K}$

$T_{r}$ : Torque, $\mathrm{N} \cdot \mathrm{m}$

$y$ : Diameter ratio of cylinder and vessel

$z: \quad$ Coordinate of $z$-direction (vertical direction)

$\gamma$ : Shear rate, $\mathrm{s}^{-1}$.

\section{Acknowledgments}

This work was financially supported by Grant-in-Aid for Scientific Research to S. Hashimoto (Young Research, B, 


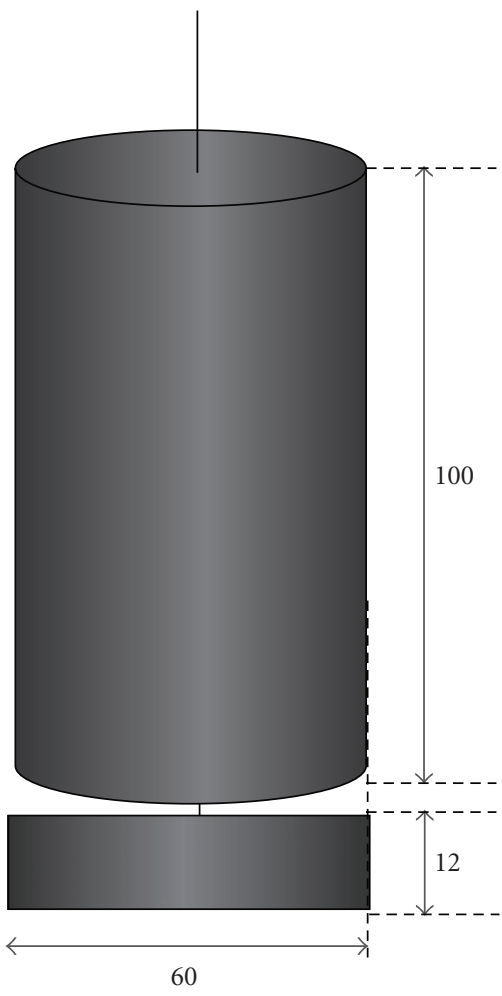

(a)

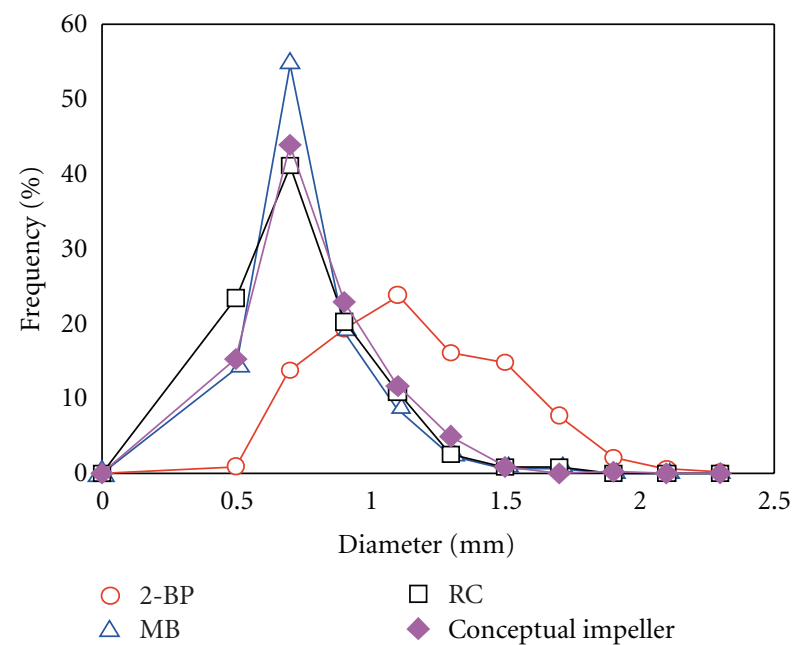

(c)

Vector magnitude

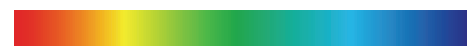

High

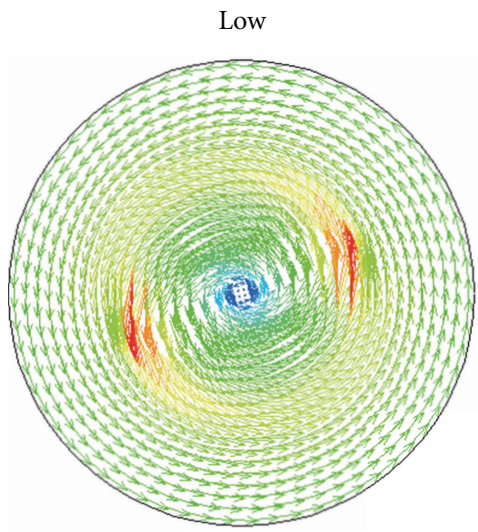

Horizontal $(z=0.01)$

(b)

FIGURE 7: The summary of conceptual impeller for efficient preparation of TBAB hydrate slurries; (a) schematic illustration of impeller (the unit of length is $\mathrm{mm})$, (b) flow velocity-vector patterns $\left(n_{r}=300 \mathrm{rpm}\right),(\mathrm{c})$ particle diameter and its distribution $\left(n_{r}=300 \mathrm{rpm}\right)$.

22760581). One of the authors (S. Hashimoto) expresses his special thanks to Dr. H. Oka (RFLOW, Co., Ltd.) for the numerical simulation by use of commercial CFD software, Rflow.

\section{References}

[1] S. Kilkis and B. Kilkis, "An analytical, multi-objective an optimization algorithm for energy efficiency in district cooling systems and green buildings," ASHRAE Transactions, vol. 117, pp. a13/1-a13/8, 2011.
[2] S. Fukusako, Y. Kozawa, M. Yamada, and M. Tanino, "Fundamental researches and developments on fine crystallineice slurries," Transactions of the Japan Society of Refrigerating and Air Conditioning Engineers, vol. 17, no. 4, pp. 413-437, 2000.

[3] S. Fukushima, S. Takao, H. Ogoshi et al., "Development of High-density Cold Latent Heat with Clathrate Hydrate," NKK Technical Report, vol. 166, pp. 65-70, 1999 (Japanese).

[4] L. S. Aladko, Y. A. Dyadin, T. V. Rodionova, and I. S. Terekhova, "Clathrate hydrates of tetrabutylammonium and tetraisoamylammonium halides," Journal of Structural Chemistry, vol. 43, no. 6, pp. 990-994, 2002. 
[5] W. Shimada, T. Ebinuma, H. Oyama et al., "Separation of gas molecule using tetra- $n$-butyl ammonium bromide semiclathrate hydrate crystals," Japanese Journal of Applied Physics, vol. 42, no. 2A, pp. L129-L131, 2003.

[6] W. Shimada, M. Shiro, H. Kondo et al., "Tetra- $n$-butylammonium bromide-water (1/38)," Acta Crystallographica Section C, vol. 61, no. 2, pp. o65-o66, 2005.

[7] S. Hashimoto, S. Murayama, T. Sugahara, H. Sato, and K. Ohgaki, "Thermodynamic and Raman spectroscopic studies on $\mathrm{H}_{2}+$ tetrahydrofuran+water and $\mathrm{H}_{2}+$ tetra-n-butyl ammonium bromide+ water mixtures containing gas hydrates," Chemical Engineering Science, vol. 61, no. 24, pp. 7884-7888, 2006.

[8] S. Hashimoto, T. Sugahara, M. Moritoki, H. Sato, and K. Ohgaki, "Thermodynamic stability of hydrogen + tetra- $n$ butyl ammonium bromide mixed gas hydrate in nonstoichiometric aqueous solutions," Chemical Engineering Science, vol. 63, no. 4, pp. 1092-1097, 2008.

[9] S. Hashimoto, T. Tsuda, K. Ogata, T. Sugahara, Y. Inoue, and K. Ohgaki, "Thermodynamic properties of hydrogen + tetra- $n$ butyl ammonium bromide semi-clathrate hydrate," Journal of Thermodynamics, vol. 2010, Article ID 170819, 5 pages, 2010.

[10] H. Oyama, W. Shimada, T. Ebinuma et al., "Phase diagram, latent heat, and specific heat of TBAB semiclathrate hydrate crystals," Fluid Phase Equilibria, vol. 234, no. 1-2, pp. 131-135, 2005.

[11] M. Darbouret, M. Cournil, and J. M. Herri, "Rheological study of TBAB hydrate slurries as secondary two-phase refrigerants," International Journal of Refrigeration, vol. 28, no. 5, pp. 663671, 2005.

[12] S. I. Kondo, M. Motoda, K. Takahashi, and H. Horiguchi, "The influence of the bottom shape of an agitated vessel stirred by dual impellers on the distribution of solid concentration," Journal of Chemical Engineering of Japan, vol. 40, no. 8, pp. 617-621, 2007.

[13] K. Shimizua, K. Takahashi, E. Suzukia, and T. Nomura, "Effect of baffle geometries on crystal size distribution of aluminum potassium sulfate in a seeded batch crystallizer," Journal of Crystal Growth, vol. 197, no. 4, pp. 921-926, 1999.

[14] A. Barresi and G. Baldi, "Solid dispersion in an agitated vessel," Chemical Engineering Science, vol. 42, no. 12, pp. 2949-2956, 1987.

[15] A. B. Metzner and R. E. Otto, "Agitation of non-Newtonian fluids," AIChE Journal, vol. 3, no. 1, pp. 3-10, 1957.

[16] N. Kamei, S. Hiraoka, Y. Kato et al., "Development of power correlations for various impellers in an agitated vessel in laminar region based on a numerical analysis of 2-D flow," Kagaku-kogaku Ronbunshu, vol. 20, no. 5, pp. 595-603, 1994 (Japanese).

[17] T. N. Zwietering, "Suspending of solid particles in liquid by agitators," Chemical Engineering Science, vol. 8, no. 3-4, pp. 244-253, 1958. 

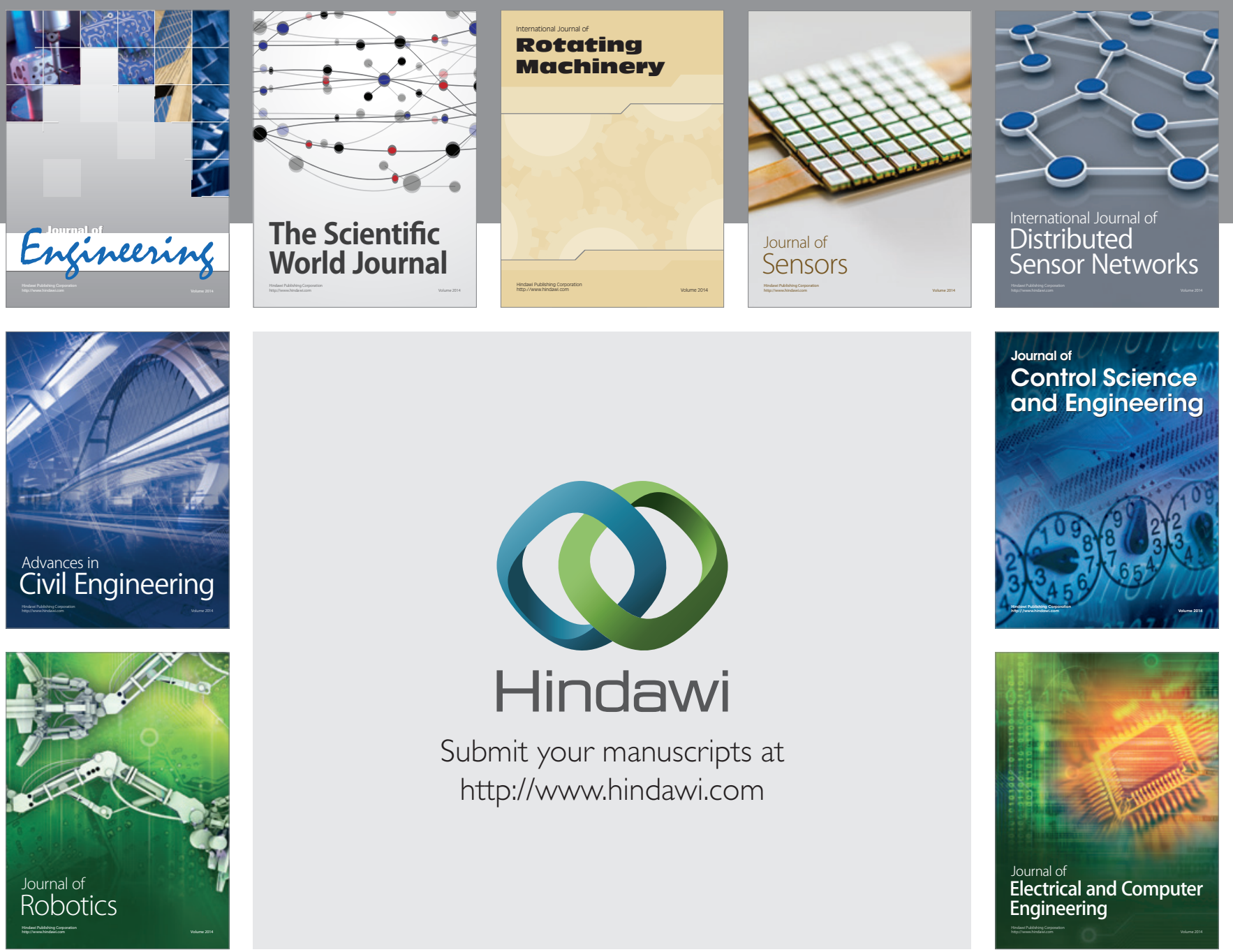

Submit your manuscripts at

http://www.hindawi.com
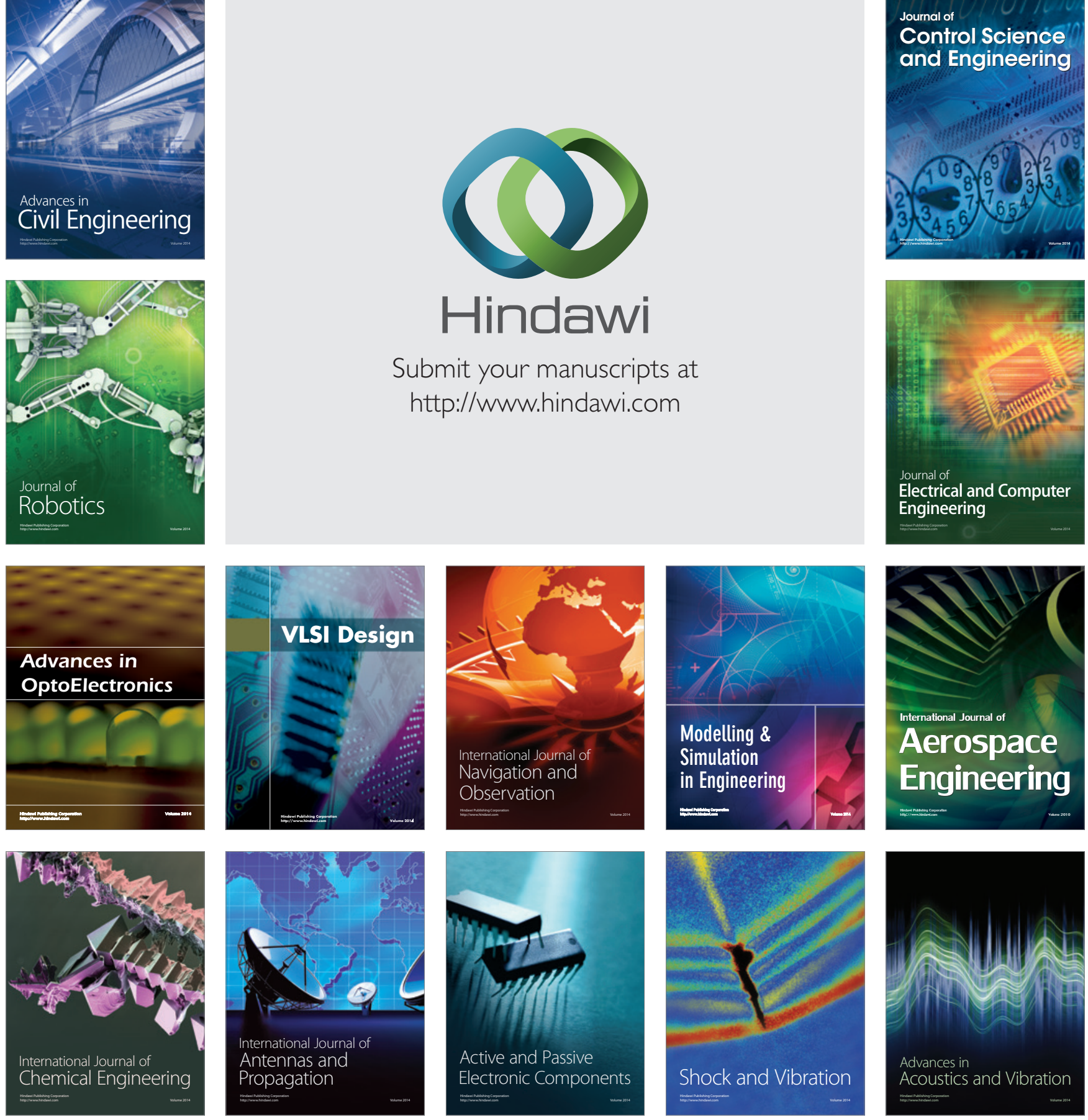